\title{
A CONSTITUIÇÃO DA MEMÓRIA DOS PROCEDIMENTOS EM SAÚDE NO CONTEXTO DO PRONTUÁRIO ELETRÔNICO DO PACIENTE
}

\author{
LA CONSTITUCIÓN DE LA MEMORIA DE LOS \\ PROCEDIMIENTOS EN SALUD EN EL CONTEXTO DEL \\ HISTORIAL CLÍNICO ELECTRÓNICO DEL PACIENTE
}

Rosane Suely Alvares Lunardelli - lunardelli@uel.br Doutora em Estudos da Linguagem pela Universidade Estadual de Londrina (UEL). Professora do Departamento de Ciência da Informação da UEL.

Izângela Maria Sansoni Tonello - izangela@uel.br Mestre em Gestão da Informação pela Universidade Estadual de Londrina (UEL). Docente do Departamento de Ciência da Informação da UEL.

Letícia Gorri Molina - Igmolina@uol.com.br Doutora em Ciência da Informação pela Universidade Estadual Paulista (UNESP/Marília). Docente do Departamento de Ciência da Informação da Universidade Estadual de Londrina (UEL).

\section{RESUMO}

Introdução: Estudos realizados por diversas áreas do conhecimento em torno da memória evidenciam a importância de que se reveste esse tema para a sociedade contemporânea, extremamente fértil no que diz respeito à produção de novos conhecimentos e possíveis esquecimentos também.

Objetivo: Nesse contexto, buscou-se caracterizar o prontuário eletrônico do paciente como valioso documento de constituição da memória da saúde da população.

Metodologia: Apoiados em fundamentos teóricos relativos aos processos e tipos de memória foram apresentados alguns dos atributos do prontuário eletrônico do paciente, suas funções, finalidades e seu papel como um dos lugares de memória. 
Resultados: Inserido em categorias de memória no que diz respeito à sua abrangência, tempo de duração, mecanismos de criação e conteúdo, defende-se que o prontuário deva ser considerado, na contemporaneidade, como agente de constituição e preservação da memória procedimental.

Conclusões: De acordo com o panorama apresentado, espera-se que as questões abordadas suscitem reflexões e promovam outros estudos a respeito desse documento aqui instituído como um dos mais significativos lugares de memória, de estabelecimento e preservação das ações, dos procedimentos realizados no âmbito dos cuidados em saúde.

Palavras chave: Prontuário do paciente. Prontuário Eletrônico do Paciente. Memória. Memória Procedimental.

\section{INTRODUÇÃO}

A imensa quantidade de informações relacionadas ao atendimento à saúde da população reveste-se de características que as particularizaram uma vez que são decorrentes de estudos e pesquisas, das ações realizadas pelos diversos profissionais da Área, bem como daqueles envolvidos com o setor de administração nas mais variadas esferas. Essas informações abarcam questões acerca da saúde do paciente e todas variáveis que compõem esse processo.

No âmbito de atuação dos serviços em saúde, essas informações geralmente são/estão compiladas, organizadas e registradas em prontuários, o que concorre para sua efetiva e eficaz localização e utilização. Os prontuários dos pacientes são compostos por documentos produzidos em função das anotações de diagnósticos, resultados de exames, condutas empregadas no decorrer do atendimento e tratamento dos pacientes. As informações aí contidas subsidiarão a continuidade do tratamento, quais procedimentos incidiram positivamente nesse processo.

Além de auxiliarem as práticas clínicas e administrativas, tornam-se relevantes repositórios de dados e informações para a pesquisa histórica e científica uma vez que seus conteúdos revelam novos procedimentos realizados, novas tecnologias e novas estratégias de gestão em saúde. (GALVÃO; RICARTE, 2011)

De acordo com o exposto, é proposta do estudo apresentar os prontuários, lócus do registro dos procedimentos voltados à saúde -, como importante documento de constituição da memória da saúde ou como defende Nora (1997), lugares de memória, especialmente no que diz respeito aos procedimentos utilizados para o 
atendimento à população. Nesse sentido cabe lembrar que esse documento instituise como a memória registrada da história dos pacientes e, portanto, de extrema importância para a comunicação entre os diversos setores e profissionais responsáveis pelos atendimentos realizados.

\section{MEMÓRIA}

O tema memória tem sido estudado por diferentes áreas do conhecimento, das quais se originam várias concepções. Desde a Antiguidade, foi considerada como fonte de conhecimento e de sabedoria e os estudos a esse respeito eram de suma importância, uma vez na época não havia sido inventada a imprensa e a leitura demandava memorização. (MURGIA, 2010)

Segundo Chapouthier (2005), o termo memória pode assumir dois sentidos: o primeiro seria a capacidade que seres vivos têm de armazenar dados, informações e conhecimentos a respeito do mundo em que vive e assim modificar o próprio comportamento e, - sob uma acepção mais ampla -, a memória seria entendida como toda marca deixada no mundo ou em parte deste, por determinado acontecimento, como "[...] traços, resíduos ou fósseis, bem como de memória genética, citoplasmática ou imunológica". (p.9)

Complementando a tese apresentada acrescenta-se outro sentido à palavra memória: a concepção e existência de memórias criadas pelo ser humano, as memórias artificiais.

Reportando-se à Le Goff, Lucas (1998, p. 92) esclarece que o termo memória assume as seguintes conotações:

a de testemunho administrativo (dossiê) a serviço do poder (o rei); a serviço das artes e da literatura; a serviço do indivíduo (memória pessoal para as gerações futuras); a serviço da opinião pública ( memória jornalística); a serviço da ciência médica e do ensino ( a memória como capacidade do ser humano armazenar conhecimento); a serviço do homem através das máquinas ( memória agregada - a atual memória dos computadores). ( grifo nosso)

Dodebei e Gouveia (2008, p.4), avaliam que os estudos mais atuais relativos à memória desenvolvem-se em uma perspectiva transdisciplinar, permitindo às 
diferentes áreas do conhecimento dialogar entre si. Isso acontece talvez pelo fato de as primeiras investigações ocorrerem em torno da possibilidade de lembrar e esquecer, temas estudados por diferentes áreas do conhecimento. Dando continuidade as reflexões, Dodebei (2010), em uma perspectiva da cronologia dos acontecimentos, informa que "[...] é somente a partir do século XX que o mundo é visto como um espaço informacional e memorial, em que os aspectos materiais e imateriais dos objetos criados pelas sociedades entram em disputa". É nesse momento, que a produção cultural e social começa a ter valor de memória, resgatados e ligados à sociedade que a produz.

Grippa (2010) considera que a memória possibilita o resgate de algo relacionado ao passado, com o intuito de compará-lo com os dados do presente. Ela proporciona a preservação de determinadas informações essenciais para a experiência individual e o conhecimento de natureza científica, filosófica ou técnica. A memória, segundo a autora, "é considerada o único instrumento, no qual, ideias e palavras podem ser reunidas, fugindo assim do império do imediato" (p.81). Sem ela, não mais existiriam as relações sociais, assim como a própria noção de sociedade e "por fim, desapareceriam as identidades individuais e coletivas, assim como a própria possibilidade de conhecimento" (p.81) ou da construção do conhecimento. Nesse sentido, Grippa lembra que as diversas formas de conhecimento existentes são fruto das formas de organização da memória de um conhecimento de uma época específica.

Por ser objeto de interesse de várias áreas do conhecimento, como anteriormente mencionado, existem concepções diferenciadas no que diz respeito à tipologia e atributos de que se reveste a memória. Como afirma Izquierdo (1989), existem tantos tipos de memória quanto existem tipos de experiências acumuladas. Entretanto, como ressalta o autor, "há algo em comum entre todas essas memórias: a conservação do passado através de imagens ou representações que podem ser evocadas". (p.89)

Ao referir-se à memória e sua abrangência, Ribeiro (2010, p. 41) argumenta que é possível caracterizá-la a partir de dois enfoques: "a memória individual (lembranças, conexões dos fatos com a própria vivência dos membros em suas comunidades) e a memória coletiva (conjunto de acontecimentos de um grupo limitado no espaço e no tempo)". 
Outras pesquisas realizadas em torno da memória evidenciam a dicotomia necessária ao entendimento dessa temática. Nesse caso, têm-se a memória biológica e memória artificial. A biológica seria a memória humana, interna e a memória artificial se constituiria naquela externa, física, cristalizada em suportes exteriores ao cérebro humano.

Draaisma (2005, n.p.) ao referir-se à memória artificial, a considera como relevante possibilidade de preservação do acontecido uma vez que "[...] não só recebem, aliviam e ocasionalmente substituem a memória natural, mas também têm dado forma ao nosso modo de encarar a recordação e o esquecimento".

Estudos a respeito dos tipos de memória biológica utilizam como critérios, o tempo de duração e conteúdo de cada uma delas. Com relação ao tempo de retenção da informação, de permanência na memória, têm-se as memórias de curto e longo prazo. A memória de curta duração ou curto prazo está relacionada à informação instantânea, que sobrevive o tempo necessário apenas para a informação ser utilizada, ou como esclarece Pinto (2001, p.8), é aquela responsável pelo "processamento e permanência temporária da informação para efeitos de conclusão das tarefas em curso". Dada sua dupla função de retenção e processamento da informação, Baddeley (1986, p. 34), citado por Pinto (2001, p.8) denomina a memória de curto prazo de memória operatória e a concebe como "um sistema de armazenamento e manipulação temporária da informação durante a realização de um conjunto de tarefas cognitivas como a compreensão, aprendizagem e raciocínio".

Para Izquierdo (2002), a partir de quatro a seis horas (prazo em que se pode estimar sua duração máxima) a memória de curto prazo passa a ser gradativamente substituída pela memória de longa duração, cujo prazo de retenção é por tempo ilimitado. Sem ela "[...] não haveria nada - nenhum livro, nenhuma televisão, nenhuma aprendizagem, e nenhuma comunicação". (BORTOLI; CASTRO; TRUJILLO, s.d., p.1)

$\mathrm{Na}$ perspectiva de seu conteúdo, Izquierdo (2004), afirma que existem basicamente dois grandes tipos de memória: as declarativas ou explícitas (um texto, um fato, um evento, muitos fatos, rostos, conhecimentos) e as memórias de procedimentos, procedural ou implícitas, consideradas por alguns estudiosos como sendo hábitos adquiridos e evocados em muitas situações, de modo inconsciente. 
A memória declarativa ou explícita, inserida na categoria de memória de longo prazo, é a memória para fatos, textos, números de telefones, entre outros. Abrange tudo que é possível evocar por meio de palavras. Subdivide-se em episódica (relacionada a eventos e datas) ou semântica (relaciona-se a memória do significado das palavras de palavras). Essa modalidade requer participação consciente.

A memória implícita, segundo Schacter (1987), é revelada quando experiências anteriores facilitam o desempenho de tarefas que não exigem lembranças conscientes ou intencionais. Em contrapartida, a memória explícita é revelada quando, para o desempenho de uma tarefa, requer recordação consciente de experiências anteriores.

A implícita, não declarativa, ou de procedimentos, é aquela memória de competências e hábitos uma vez que evoca habilidades aprendidas de forma mecânica, dicas de palavras, associações e que não requer participação consciente. É a memória de armazenamento de procedimentos e habilidades. Uma importante característica da memória procedural, outro termo utilizado para memória procedimental, é que ela funciona implicitamente. O comportamento habitual é executado automaticamente e, portanto, inconscientemente. À medida que a memória procedural é tornada explícita, ela se transforma em algo mais, é traduzida para a forma semântica ou episódica (SILVA et al, 2003, p.62).

Esse tipo de memória diferencia-se da declarativa, já que não precisa ser verbalizada (declarada). "A memória declarativa (para datas ou fatos e outros eventos) é mais fácil de se formar, mas ela é facilmente esquecida, enquanto que a memória procedural [procedimental] tende a requerer repetição e prática, mas se mantém por mais tempo". (BORTOLI; CASTRO; TRUJILLO, s.d., p.6)

As diferentes tipologias criadas por diversos estudiosos a respeito da memória, reitere-se, demonstra sua plasticidade no que diz respeito às concepções a ela atribuídas.

Entretanto, dada as características e abrangências do presente estudo, optouse por apresentar os tipos de memória mais elencados nas publicações científicas. Com o intuito de sintetizar as concepções acerca dos tipos de memória e sua hierarquização, elaborou-se um esquema como se segue: 
Figura 1 - Tipos de memória

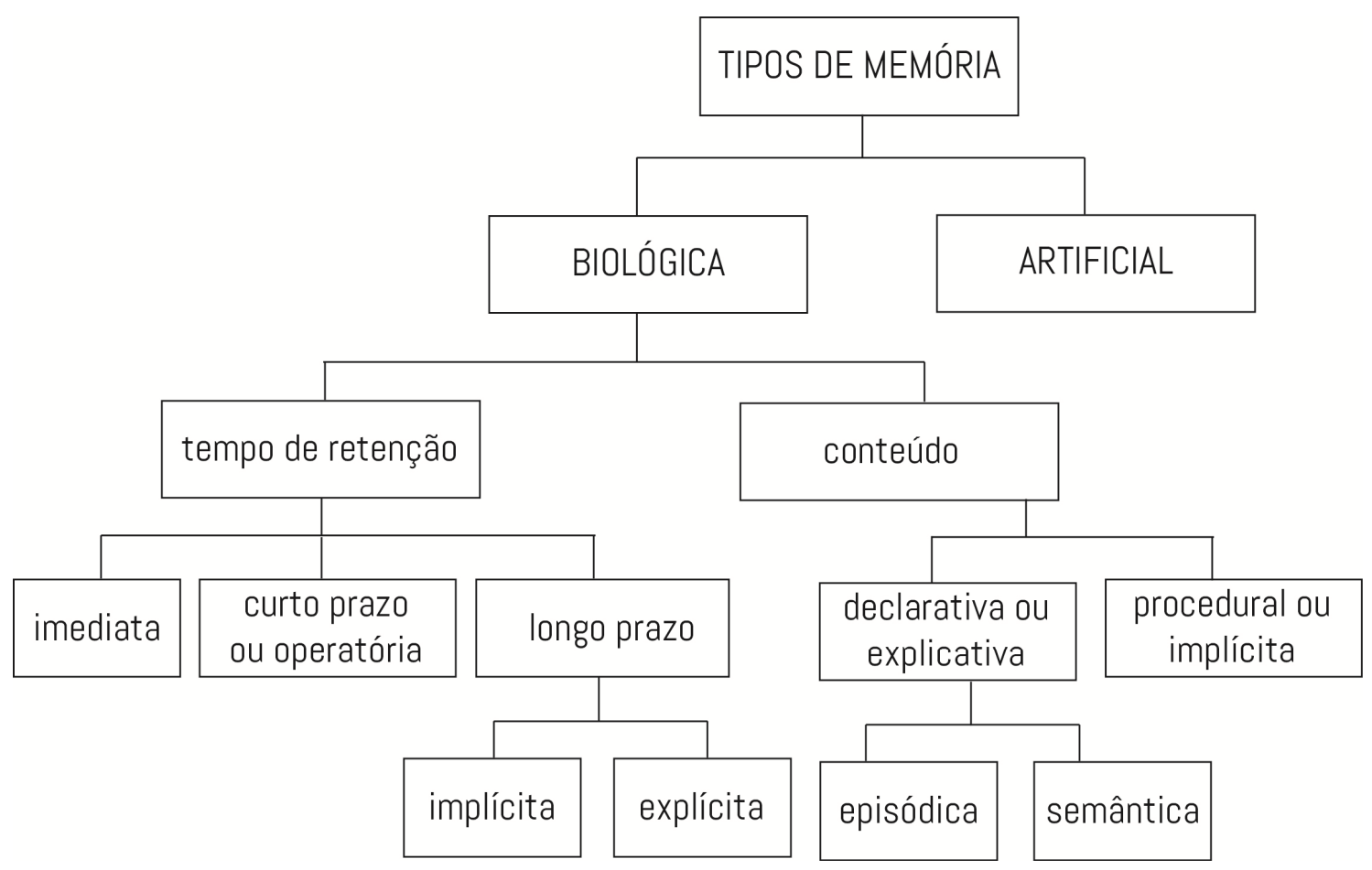

Fonte: elaborado pelas autoras

Tomando como empréstimo os conceitos, as concepções acima expostas e trazendo-as para o âmbito do prontuário do paciente, observou-se que seria possível caracterizá-lo como documento de grande valia no que diz respeito à constituição da memória procedimental dos atendimentos realizados em uma instituição de saúde. Nesse sentido, importa mencionar que o entendimento a respeito desse tipo de memória no estudo em tela, difere, em certo grau, daquela que subjaz aos trabalhos de Tulving (1985), entre outros. Para o autor, citado por Pinto (2001, p.1) a "memória procedimental seria constituída por capacidades perceptivas e motoras que no decurso do tempo e com a prática se transformaram em rotinas e hábitos e que de pouco ou nada se tem consciência." (grifo nosso)

A proposta do estudo, entretanto, busca conceber memória procedimental como o estabelecimento, o registro (a cristalização) dos métodos desenvolvidos, das condutas realizadas, - de modo consciente -, na promoção à saúde. Defende também que esse tipo de memória de longa duração estaria inserida em duas categorias mais amplas, ou seja, a da memória coletiva e artificial. 
Outra concepção a ser mencionada diz respeito à inserção do prontuário na categoria de espaços de memória, lugares funcionais, a que pertencem os manuais, as autobiografias ou as associações, (NORA, 1997, tradução nossa)

Pierre Nora, historiador francês, com grande importância para os estudos da História, propôs a utilização do termo "lugares de memória" para caracterizar os espaços físicos e/ou simbólicos nos quais se cristalizaria a memória. De acordo com o autor, "São lugares, com efeito nos três sentidos da palavra, material, simbólico e funcional, simultaneamente, somente em graus diversos". (1993, p.21) Esses lugares, para Nora (1997, v.2, p.2226, tradução nossa), seriam então "toda unidade significativa, de ordem material ou ideal que a vontade dos homens ou o trabalho do tempo converteu em elemento simbólico do patrimônio memorial de uma comunidade qualquer".

Tais espaços na perspectiva de Murgia (2010,p.viii) teriam assim uma importante função simbólica, "no sentido de representar dentro de uma cidade ou espaço dedicado à recordação social e uma função informacional, no sentido de lembrar os acontecimentos, pessoas e lugares que realmente existiram e cujas provas podemos encontrar nesses lugares".

Nos trabalhos de Nora, fica evidente que a criação da categoria lugares de memória decorreu da sua percepção a respeito da apropriação, pelo discurso histórico, da categoria memória. Segundo o historiador, (1993, p.7) "fala-se tanto de memória porque ela não existe mais". Nesse sentido então, propõe a inscrição de fatos, situações ou momentos em um dado espaço e esclarece que "É a desritualização de nosso mundo que faz aparecer a noção". (p.13)

Murgia (2010, p.8), ao justificar a proposta de Nora, menciona que

Perante as mudanças expressas pela modernidade da sociedade industrial, a forma de transmissão da memória coletiva perdeu seus canais, seus meios. Esse desaparecimento fez com que fosse necessário a criação de espaços ou lugares de memória.

Para Arévalo (2004, p.8) Nora emprega a noção de lugares de memória, "na esperança de que essa possa reunificar o indivíduo fragmentado com o qual lidamos na sociedade contemporânea". Em sua obra, Nora autoriza tal premissa ao afirmar que "lugares de memória nascem e vivem do sentimento que não há memória 
espontânea, que é preciso criar arquivos, que é preciso manter aniversários, organizar celebrações, [...] notariar atas, porque essas operações não são naturais". (NORA, 1993, p.13)

\section{PRONTUÁRIO DO PACIENTE}

Considerado como o mais significativo meio de interlocução entre os membros da equipe de uma instituição voltada à saúde da população, a prática de registro de informações a respeito dos atendimentos prestados, vem sendo realizada, há muitos anos. O prontuário do paciente, nessa perspectiva, é considerado como um dossiê, cujo conteúdo evidencia diversas informações a respeito de um determinado paciente, suas características, suas queixas e o tratamento a ele prescrito pelos profissionais que o atenderam. Em decorrência, os prontuários são considerados repositórios informacionais de extrema relevância no atendimento à saúde da população, como importantes fontes de informação a respeito de determinada patologia, seu histórico, desenvolvimento, prescrições, curas ou medidas paliativas, entre outros aspectos relacionados.

O valor probatório desse documento também deve ser destacado, pois, como indica o Conselho Regional de Medicina do Estado de Santa Catarina (2000, p. 1), o prontuário "[...] tem sido a principal peça de defesa do médico nos casos de denúncias por mau atendimento com indícios de imperícia, imprudência ou negligência, ou seja, na presunção da existência de erro médico".

Outra questão a ser evidenciada diz respeito à sua importância, caso o hospital ou a clínica médica, "além dos tratamentos realizados, dedicarem-se também ao uso e compartilhamento das informações geradas em seus prontuários, como fonte de estudo, de pesquisa" (MOLINA; LUNARDELLI, 2010, p.74).

Fruto de uma construção coletiva, produto do trabalho realizado por diversos profissionais, o prontuário do paciente é considerado por Bentes; Soares (2010, p.14), "um documento de informação e comunicação para o campo da saúde".

Para Stumpf; Freitas (1997), o prontuário precisa ser estruturado de tal maneira que atenda as necessidades dos diferentes profissionais envolvidos no processo, ao apresentar informações quando, onde e como esse profissional necessitar, nas mais diversas atividades. 


\section{Essas demandas segundo os autores (1997, p.37)}

incluem o apoio à equipe médica, para a tomada de decisão diagnóstica e terapêutica; o suporte aos pesquisadores, na busca de dados para pesquisas relevantes; aos professores, nas atividades didáticas, nas quais a técnica de estudo de casos é muito utilizada; aos administradores, nas tarefas de faturamento e emissão de relatórios gerenciais e para prover o suporte legal, quando necessário.

Marin (2010, p. 23), em um âmbito mais abrangente, discorre acerca do papel do prontuário do paciente na construção e preservação da saúde populacional ao argumentar que "[...] pode-se até mesmo afirmar que o sistema de saúde de um país é estabelecido graças ao que se tem documentado em um prontuário, uma vez que dele são extraídas as informações sobre a saúde dos indivíduos que formam uma comunidade, uma nação".

De acordo com essa linha de raciocínio pode-se afirmar que o prontuário devidamente preenchido e atualizado, torna-se de suma importância para o paciente, para a instituição, para a equipe de saúde, para o ensino e pesquisa e consequentemente, para a construção do registro e da memória dos procedimentos realizados (POSSARI, 2008).

Para o paciente, possibilita atendimento, obtenção do diagnóstico e tratamentos mais eficientes e eficazes. Representa excelente instrumento de defesa em caso de reivindicações perante o médico, o hospital, bem como aos poderes públicos. Para a instituição, gera maior lucro, uma vez que possibilita o uso racional dos medicamentos, instrumentos e serviços especializados, bem como também subsidia sua defesa no caso de possíveis acusações já que se constitui em documento comprovatório do atendimento realizado. É também para a instituição, um demonstrativo fidedigno do padrão de qualidade do atendimento prestado.

No que tange à equipe de saúde, o prontuário é considerado o mais eficiente meio de intercomunicação, pois fornece informações de suma importância por meio do registro do estado evolutivo dos cuidados, quais procedimentos resultaram em melhoria ou não do estado do paciente, enfim, as condutas terapêuticas realizadas.

Para o ensino e a pesquisa torna-se valiosa fonte de informações acerca de dados estatísticos de incidências e prevalências, de morbidades e mortalidades. Possibilita também o cotejamento entre as diferentes condutas terapêuticas e 
análises quanto à sua eficiência. A reunião dos aspectos abordados possibilita ao prontuário tornar-se um repositório de dados, de informações e conhecimentos, que o tornam um relevante agente na constituição e preservação da memória da instituição, ao registrar os serviços oferecidos, equipamentos, instrumentos utilizados e em especial os procedimentos empregados no atendimento à saúde e os resultados obtidos.

Bertolli Filho (2006, p. 15) salienta a relevância dos prontuários ao afirmar que "[...] no rol de documentos constitutivos dos arquivos médicos, afloram como peças preciosas que possibilitam fixar cenários, confirmar saberes e desvelar sensibilidade, enfim, viabilizar novas possibilidades de apreensão da memória da Saúde [...]".

Caracterizado como documento único, de característica multimídia (composto por textos escritos, imagéticos), multifuncional (gerado e utilizado com diversas finalidades) e multiprofissional (registrado e consultado por vários profissionais da Área), atualmente o prontuário, em muitas instituições de saúde, está sendo criado e utilizado em meio eletrônico.

Denominado prontuário eletrônico do paciente, ou simplesmente PEP, "pode ser entendido como sendo a estrutura eletrônica para manutenção de informação sobre o estado de saúde e o cuidado recebido por um indivíduo durante todo seu tempo de vida" (MARIN, 2010, p.29). Nessa mesma linha de raciocínio, a autora (2003, p. 75) enfatiza que "a proposta básica do PEP é unir todos os diferentes tipos de dados produzidos em variados formatos, em épocas diferentes, feitos por diferentes profissionais da equipe de saúde em distintos locais".

Sabatini (2002), citado por Bentes Pinto (2006, p.37) argumenta que, com chegada dos dispositivos eletrônicos, o PEP, passou a ser considerado "um instrumento ativo, uma central de serviços de informação, um promotor de saúde e de prevenção de problemas, e um educador de pacientes e divulgador de informações confiáveis sobre medicina e saúde".

A crescente utilização do PEP em instituições de saúde, segundo Galvão e Ricarte (2011, p.80) decorre, entre outros fatores, da proposta de integralidade da atenção à saúde, uma vez que "não se justifica, por exemplo, que o mesmo paciente atendido em instituições de saúde distintas ou em diferentes localidades tenha suas informações dispersas e desconectadas". Tal situação impede "que os profissionais 
da saúde tenham uma visão integral de seu perfil e bem estar, requerendo, portanto, uma maior exposição do paciente para coleta de informação, repetição desnecessária de exames e duplicação de informações que já foram devidamente coletadas por outros profissionais e instituições" (GALVÃO; RICARTE, 2011, p.80)

A esse respeito, Marin (2010, p.29) complementa, ao argumentar que "além da integração, um dos requisitos básicos [dos prontuários] é a interoperabilidade, que é a habilidade de dois ou mais sistemas computacionais trocarem informações". Em decorrência, observa-se que as vantagens do PEP em relação ao prontuário no formato tradicional são comprovadamente mais relevantes, destacando-se, - como já mencionado -, a integração dos dados, o que constitui um atributo essencial na qualidade dos cuidados ao paciente e dos serviços prestados no sistema de saúde. Outra vantagem considerável também é a diminuição do volume documental e consequentemente, do espaço físico que o prontuário de papel demanda.

As informações que compõem o prontuário, de acordo com Moraes e Salies (2009, p.427), constituem-se em um "grande banco de dados à espera de processamento, pronto para gerar pesquisas sobre as doenças e seus tratamentos, assim como pesquisas para melhoria de procedimentos de cuidados, de eficácia de medicamentos e materiais, etc." Ao evidenciar seu caráter probatório, Cruz; Flores; Garcia, (2011, p.94-95), lembram que o prontuário eletrônico do paciente pode ser considerado como um documento que "além de servir como fonte de pesquisa na área de saúde, também pode ser utilizado como fonte de pesquisas históricas, sociológicas e arquivísticas. Ele possui atributos que demonstram como é tratada a saúde da população em determinados eventos históricos". Para os autores citados, o prontuário eletrônico é considerado componente da memória patrimonial e cultural de um indivíduo e de uma instituição, a qual deve ser responsável por sua preservação. Em outros termos, Roger e Gaunt (1994, p. 190) ratificam a proposição ao mencionarem que o PEP "pode ser definido como a memória eletrônica das informações relacionadas a um paciente, identificáveis, acessíveis por computador e constantemente atualizadas". 


\section{COMENTÁRIOS FINAIS}

Preservar os registros dos dados, informações e conhecimentos gerados em diferentes áreas do conhecimento é essencial para a sobrevivência e desenvolvimento do ser humano. Nesse sentido, os prontuários gerados em instituições voltadas à área da saúde e, especialmente aqueles em meio eletrônico, constituem-se em documentos de extrema importância para a qualidade do atendimento prestado ao paciente, para pesquisa médica, administrativa, jurídica e acadêmica. De outra perspectiva, permite ainda, o resgate da história dos serviços prestados, dos tratamentos oferecidos, caracterizando-se como elemento chave na comprovação dos procedimentos realizados no decorrer do tempo, em determinadas patologias, diferentes contextos e regiões, no âmbito da saúde. É campo para pesquisa e fonte de dados estatísticos acerca de determinada patologia, sua incidência, prevalência e mortalidade. Torna possível a verificação e comparação dos tratamentos e permite estabelecer uma análise da sua eficiência ou ineficiência

De acordo com essa linha de raciocínio, foi proposta desse estudo, caracterizado como pesquisa bibliográfica sem delimitação temporal, de tipo de fonte consultada ou de área do conhecimento - qualifica-lo como um dos veículos mais importantes de constituição da memória procedimental de uma instituição de saúde. Vale lembrar que a mais relevante finalidade dos registros nesse dossiê é o compartilhamento de dados, informações e conhecimentos relacionados ao paciente e ao tratamento prescrito.

( GALVÃO; RICARTE, 2012)

A memória procedimental, aqui entendida de forma diferenciada do que aquela apresentada por autores de outras áreas, conforme mencionado anteriormente, seria o registro, a conservação, a cristalização das ações, dos procedimentos efetuados em contextos de ensino, pesquisas e cuidados aos pacientes atendidos.

Os prontuários, nessa ótica, constituem-se em lugares de memória, no sentido dado por Nora $(1993,1997)$, visto que são considerados espaços físicos (materiais) que funcionam como suporte para a constituição da memória coletiva (imaterial) da área da saúde e mais especificamente dos procedimentos realizados nesse contexto. 
Ainda em sua fase embrionária, espera-se que as premissas aqui apresentadas, promovam a continuidade e o aprofundamento dessas reflexões e com isso, possibilitem a criação de outras concepções e categorizações a respeito do prontuário e sua importância na constituição da memória em saúde, pois como bem afirmou Le Goff (1994), cabe à memória, ao salvar o passado, prestar serviços ao presente e ao futuro.

Agradecimentos: Ao CNPq pelo auxílio financeiro à pesquisa na qual o estudo está vinculado

\section{REFERÊNCIAS}

ARÉVALO, M.C. da M. Lugares de memória ou a prática de preservar o invisível através do concreto. I Encontro Memorial do Instituto de Ciências Humanas e Sociais. Anais...Mariana, 10 de nov. 2004.

BENTES PINTO, V. Prontuário eletrônico do paciente: documento técnico de informação e comunicação do domínio da saúde. Enc. Bibli: R.Eletr. Bibliotecon. Cl. Inf., Florianópolis: v.11, n.21, p. 34-48, 2006.

; SOARES, M.E. Informação para a Área de Saúde: o prontuário do paciente, ontologia de imagem, terminologia, legislação e gerenciamento eletrônico de documentos. Fortaleza: Edições UFC, 2010.

BERTOLLI FILHO, Claudio. Prontuários Médicos e a Memória da Saúde Brasileira. In: BIS. Memória e História da Saúde em São Paulo. n. 38, p. 12 - 15, abr. 2006.

BORTOLLI, J.P de; CASTRO, P de V.; TRUJILLO, R. Distinção entre memória procedural e declarativa. (trabalho apresentado à disciplina MC 906 Inteligência Artificial) Disponível em:<http://www.ic.unicamp.br/ wainer/cursos/906/trabalhos/M3.pdf>. Acesso em 14 abril 2014.

BRASIL. CONSELHO REGIONAL DE MEDICINA DO ESTADO DE SANTA CATARINA. Manual de orientação ética e disciplinar. 2 ed. rev. Atual. Florianópolis, 2000. Disponível em: < http://www.portalmedico.org.br/regional/crmsc/manual/parte3b.htm> Acesso em: 02 dez. 2007

CHAPOUTHIER, G. Registros evolutivos. Viver mente \& cérebro, n.2, edição Especial, São Paulo: Duetto Editorial, 2005. 
CRUZ, J. A. S.; FLORES, D; GARCIA, O. M. C. O prontuário eletrônico do paciente (PEP) como memória, patrimônio documental e cultural. Em Questão, Porto Alegre, v. 17, n. 2, p. 91-99, jul./dez. 2011.

DRAAISMA, D. Metáforas da memória: uma história das ideias sobre a mente. 2.ed. Bauru: EDUSC, 2005.

DODEBEI, V.L. Memória e informação- interações no campo da pesquisa. In: MURGIA, E.I. (org). Memória: um lugar de diálogo para Arquivos, Bibliotecas e Museus. São Carlos: Compacta Gráfica e Editora, 2010, p. 59-78, 2010.

; GOUVEIA, I. Memória do futuro no ciberespaço: entre lembrar e esquecer. Rio de Janeiro, DataGramaZero: Revista de Ciência da Informação, Rio de Janeiro, v.9, n.5, out. 2008. Disponível em:

<http://www.dgz.org.br/out08/Art_02.htm>. Acesso em: 10 out. 2011.

GALVÃO, M. C. B.; RICARTE, I. L. M. O prontuário eletrônico do paciente no século XXI: contribuições necessárias da Ciência da Informação. InCID: R. Ci. Inf. e Doc., Ribeirão Preto, v. 2, n. 2, p. 77-100, jul./dez. 2011.Disponível em: < http://www.revistas.usp.br/incid/article/view/42353. Acesso em 12 de nov.2012.

GRIPPA, G. Memória: geografias culturais entre história e ciência da informação. In: MURGIA, E.I. (org). Memória: um lugar de diálogo para Arquivos, Bibliotecas e Museus. São Carlos: Compacta Gráfica e Editora, p. 79- 110, 2010.

IZQUIERDO, I. Memória. Porto Alegre: Artes Médicas, 2002.

Memórias. Estud. Av. [online]., vol.3, n.6, p. 89-112, 1989.

Disponível em: http://www.scielo.br/pdf/ea/v3n6/v3n6a06.pdf. Acesso em 10 de maio de 2014

. Tipos e mecanismos de memória. Revista Mente e Cérebro. São Paulo: dez. 2004. p. 81-87.

LE GOFF, Jacques. Memória. In:_História e Memória. Campinas: Ed. UNICAMP, p.419-476, 2003.

LUCAS, C.R. Os Senhores da Memória e do Esquecimento. Transinformação, v.10,n.1, p.87-96, jan./abril, 1998. Disponível em: < http://periodicos.puccampinas.edu.br/seer/index.php/transinfo/article/view/1567. Acesso em: 02 de jan.2014.

MARIN, H. de F. Os componentes de Enfermagem do Prontuário Eletrônico do Paciente. In: MASSAD, E.; MARIN, H. de F.; AZEVEDO NETO, R. S. de. (Ed) O prontuário eletrônico do paciente na assistência, informação e conhecimento médico. São Paulo: H. de F. Marin., 2003, p. 73 - 83. 
MARIN, H. de F. O prontuário eletrônico do paciente: considerações gerais. In: PINTO, V. B.; SOARES, M. E. (Org.). Informação para a área da saúde: prontuário do paciente, ontologia de imagem, terminologia, legislação e gerenciamento eletrônico de documentos. Fortaleza: Edições UFC, 2010. p. 23-37.

MARIN, H. de F.; MASSAD, E.; AZEVEDO NETO, R. S. de. Prontuário Eletrônico do Paciente: definições e conceitos. In: MASSAD, E.; MARIN, H. de F.; AZEVEDO NETO, R. S. de. (Ed) O prontuário eletrônico do paciente na assistência, informação e conhecimento médico. São Paulo: H. de F. Marin, 2003. p.1-20.

MOLINA, L.G ; LUNARDELLI, R.S.A.;. O Prontuário do paciente e os pressupostos arquivísticos: estreitas e profícuas interlocuções. Inf.Inf., Londrina, v.15, n.1, p.6884, jan./jun.2010. Disponível em: < http://www.uel.br/revistas/uel/index.php/informacao/article/view/4764. Acesso em: jul.2010.

MORAES, M. F. de; SALIES, L., Gestão de acesso ao prontuário do paciente. In: DUARTE, Z.; FARIAS, L.(Org). A Medicina na Era da Informação Salvador: UFBA, 2009, p. 427- 441.

MURGIA, E.I. (org). Memória: um lugar de diálogo para Arquivos, Bibliotecas e Museus. São Carlos: Compacta Gráfica e Editora, 2010.

NORA, P. Les lieux de mémoire. 4.ed. Paris: Éditions Gallimard, 1997, v.1-3.

. Entre memória e história: a problemática dos lugares. Trad. Yara A.

Khoury. Rev. Do Progr. de Estudos Pós Graduados em História e do Depto. De História: Projeto História. São Paulo, v.10, p.178, 1993.

PINTO, A. da C. Memória, Cognição e Educação: Implicações Mútuas. In: B. Detry e F. Simas (ed) Educação, cognição e desenvolvimento: textos de psicologia educacional para a formação de professores. Lisboa: Edinova, 2001, p.17-54

POSSARI, J.F. Prontuário do Paciente e os Registros de Enfermagem. 2.ed. São Paulo: látria, 2008.

RIBEIRO, L.B. Memória: um lugar de diálogo para Arquivos, Bibliotecas e Museus. In: MURGIA, E.I. (org). Memória: um lugar de diálogo para Arquivos, Bibliotecas e Museus. São Carlos: Compacta Gráfica e Editora, 2010, p. 33-44.

ROGER, France F. H, GAUNT, P. N. The need for security - a clinical view. Int J Biomed Comput, v. 35, Suppl 1, p. 189-194, 1994.

SCHACTER, D. L. Implicit memory: history and current status. Journal of Experimental Psychology Learning, Memory, and Cognition. v. 13, n. 3, p.501$518,1987$. 
SILVA, M. M. e et al. A consciência: algumas concepções atuais sobre sua natureza, função e base neuroanatômica. R. Psiquiatr. RS, v. 25'(supl. 1), p. 52-64, abr./2003.

STUMPF, M. K.; FREITAS, H. M. R. de. A Gestão da Informação em um Hospital Universitário: o processo de definição do patient core record. Rev. Adm. Contemp., Curitiba, v.1, n.1, p. 71-99, jan./abr. 1997.

\section{Title}

The memory constitution of the procedures in health in the context of the patient's electronic record

\section{Abstract}

Introduction: Studies by various knowledge areas concerning the memory demonstrate the importance of this theme to contemporary society, highly fertile with regard to the production of new knowledge and possible forgetfulness.

Objective: In this context, we sought to characterize the patient's electronic record as a valuable document of memory constitution of public health.

Methodology: Based on theoretical grounds relating to the processes and types of memory some of the attributes of the patient's electronic record were presented, its functions, aims and its role as a place of memory.

Results: Inserted into categories of memory with regard to its scope, duration, and content and creation mechanisms, it is argued that the records should be considered, in contemporary times, as the constitution and preservation of procedural memory agent.

Conclusions: According to the scenario presented, it is expected that the issues addressed raise reflections and promote further studies on this document here established as one of the most significant places of memory, of establishment and preservation of the actions, of the procedures carried out under health care.

Keywords: Patient's record. Patient's Electronic Record. Memory. Procedural memory.

\section{Título}

La constitución de la memoria de los procedimientos en salud en el contexto del historial clínico electrónico del paciente

\section{Resumen}

Introducción: Estudios realizados por diversas áreas del conocimiento acerca de la memoria demuestran la importancia de dicha temática para la sociedad contemporánea, 
extremamente fértil en lo referente a la producción de nuevos conocimientos y posibles olvidos también.

Objetivo: En ese contexto, se buscó caracterizar el historial clínico electrónico del paciente como valioso documento de constitución de la memoria de la salud de la población.

Metodología: Anclados en fundamentos teóricos relacionados a los procesos y tipos de memoria, se han presentado algunos de los atributos del historial clínico electrónico del paciente, sus funciones, finalidades y su papel como uno de los lugares de la memoria.

Resultados: El historial clínico está insertado en categorías de memoria en lo toca a la amplitud, al tiempo de duración, a los mecanismos de creación y al contenido, y, por eso, se defiende que el historial clínico electrónico debe ser considerado, en la contemporaneidad, como agente de constitución y preservación de la memoria procedimental.

Conclusiones: De acuerdo con el panorama presentado, se espera que las cuestiones tratadas susciten reflexiones y fomenten otros estudios relacionados a ese documento aquí instituido como uno de los más significativos lugares de la memoria, de establecimiento y preservación de las acciones, de los procedimientos realizados en el ámbito de la salud.

Palabras clave: Historial Clínico del Paciente. Historial Clínico Electrónico del Paciente. Memoria. Memoria Procedimental.

Recebido em: 16.09 .2014

Aceito em: 07.01.2015 